\title{
The corrosion protection afforded by rare earth conversion coatings applied to magnesium
}

\author{
Amy L. Rudd ${ }^{\mathrm{a}}$, Carmel B. Breslin ${ }^{\mathrm{a}, *}$, Florian Mansfeld ${ }^{\mathrm{b}}$ \\ ${ }^{a}$ Department of Chemistry, National University of Ireland Maynooth, Maynooth, Co. Kildare, Ireland \\ ${ }^{\mathrm{b}}$ Corrosion and Environmental Effects Laboratory (CEEL), Department of Materials Science and \\ Engineering, University of Southern California, Los Angeles, CA 90089-0241, USA
}

Received 28 September 1998; accepted 28 May 1999

\begin{abstract}
The corrosion protection afforded by cerium, lanthanum and praseodymium conversion coatings formed on pure magnesium and a magnesium alloy, WE43, has been studied using dc polarisation and ac impedance techniques. The coatings, which were formed by immersion in rare-earth salt containing solutions, reduced significantly the dissolution of magnesium in a $\mathrm{pH} 8.5$ buffer solution. With continued immersion of the treated electrodes in the aggressive $\mathrm{pH} 8.5$ solution, the coatings first appeared to become more protective, but after periods exceeding $60 \mathrm{~min}$ began to deteriorate. This is attributed to the formation of magnesium hydroxy corrosion products and mixed rare earth/magnesium oxide/ hydroxide coatings, which on continued immersion became consumed by the formation of magnesium corrosion products. (C) 2000 Elsevier Science Ltd. All rights reserved.
\end{abstract}

Keywords: Magnesium; Conversion coatings; Impedance spectroscopy; Cerium

\section{Introduction}

Magnesium and magnesium-based alloys exhibit an attractive combination of low density and high strength/weight ratio making them ideal candidates for light-

\footnotetext{
* Corresponding author. Tel.: + 353-1-708-3677; fax: + 353-1-708-3815.

E-mail address: cb.breslin@may.ie (C.B. Breslin).
} 
weight engineering applications. However, the corrosion resistance of magnesiumbased alloys is generally inadequate, and has limited the use of magnesium and its alloys [1-3].

Surface treatments, such as the formation of conversion coatings, are commonly applied to magnesium alloys in order to increase the corrosion resistance. Such processes vary from the widely used chromate/manganese dip treatment to anodic treatments in fluoride-containing baths [4].

In recent times, the search for more environmentally acceptable alternatives in surface modification processes, particularly in the case of aluminium alloys, has lead to the identification of rare earth metal salts (REMS) and especially cerium species [5-13]. Corrosion inhibition by cerium salts is generally associated with the formation and precipitation of cerium oxides or hydroxides over cathodic sites on the metal surface. These precipitates, in turn, give rise to a blocking effect and reduce the rate of the reduction reactions. This has been shown clearly for coppercontaining aluminium alloys where cerium-rich insoluble films have been identified at copper precipitates, these films precipitating from solution because of the local increase in alkalinity at the copper cathodic sites $[10,11,13]$.

In this communication, the corrosion behaviour of pure magnesium and a magnesium alloy, WE43, following treatment in cerium, lanthanum and praseodymium solutions is examined.

\section{Experimental method}

Test specimens were prepared from pure magnesium (99.9\%) and a $\mathrm{Mg}$ alloy, WE43, $(3.7-4.3 \%$ Y, $2.4-4.4 \%$ rare earths, $0.4 \% \mathrm{Zr})$. The electrodes were embedded in resin leaving an exposed surface area of 0.84 and $0.94 \mathrm{~cm}^{2}$ for pure magnesium and the alloy, respectively. The exposed surfaces were polished to a mirror finish using diamond paste. They were then cleaned in distilled water and methanol and dried under a stream of air.

The conversion coatings were formed by placing the magnesium electrodes in $50 \times 10^{-3} \mathrm{~mol} \mathrm{dm}{ }^{-3}$ solutions of $\mathrm{Ce}\left(\mathrm{NO}_{3}\right)_{3}, \mathrm{La}\left(\mathrm{NO}_{3}\right)_{3}$ or $\operatorname{Pr}\left(\mathrm{NO}_{3}\right)_{3}$ at room temperature under gentle agitation for a $5 \mathrm{~min}$ period. This resulted in the formation of a visible coating on the electrode surface. These coatings were adherent, but could be removed by scratching the surface.

The electrochemical cell consisted of a three-electrode pyrex glass cell. A saturated calomel electrode (SCE) was used as the reference electrode and high density graphite rods were used as the auxiliary electrodes. All potentials quoted are on the SCE scale.

Potentiodynamic electrochemical tests were carried out using a PAR Model 263 potentiostat. In potentiodynamic polarisation tests, the working electrode was immersed in the solution for $5 \mathrm{~min}$ and then polarised from the corrosion potential at a scan rate of $0.5 \mathrm{mV} \mathrm{s}^{-1}$ in the anodic or cathodic directions. Impedance spectra were recorded at the corrosion potential using a Solartron 1250 FRA and 1287 potentiostat. All impedance data were fit to appropriate equivalent 
circuits using a complex non-linear least squares fitting routine, using both the real and imaginary components of the data. A borate buffer solution, $0.15 \mathrm{~mol}$ $\mathrm{dm}^{-3} \mathrm{H}_{3} \mathrm{BO}_{3} / 0.05 \mathrm{~mol} \mathrm{dm}^{-3} \mathrm{Na}_{2} \mathrm{~B}_{4} \mathrm{O}_{7}, \mathrm{pH} 8.5$, was used as the test electrolyte.

\section{Experimental results}

In Fig. 1 the open-circuit potential (OCP) is shown as a function of time for pure magnesium immersed in a $50 \times 10^{-3} \mathrm{~mol} \mathrm{dm}{ }^{-3} \mathrm{Ce}\left(\mathrm{NO}_{3}\right)_{3}$ solution, $\mathrm{pH}$ 3.6. This was the least acidic solution that could be used because of the hydrolysis reactions of cerium salts. The OCP increased from approximately -1500 to about $-1410 \mathrm{mV}$, as a cerium-containing film or coating formed on the magnesium surface. The most protective coating appeared to form on the surface after an immersion period of $5 \mathrm{~min}$, as is evident from the anodic polarisation data presented in Fig. 2. Here, the anodic polarisation behaviour recorded in a $\mathrm{pH} 8.4$ borate buffer solution for untreated magnesium and magnesium treated in the cerium solution for different time intervals is shown. It can be seen that the untreated $\mathrm{Mg}$ electrode dissolved, with the measured anodic current reaching values of $3 \mathrm{~mA} \mathrm{~cm}^{-2}$ in the $-1400--1200 \mathrm{mV}$ range. The anodic current density was considerably reduced for the cerium-treated electrodes, with the lowest current, $25 \mu \mathrm{A} \mathrm{cm}{ }^{-2}$, being recorded for the $5 \mathrm{~min}$ treated electrode. Longer immersion times in the acidic cerium solution produced a less protective film, as was evident from the increase in the anodic current density recorded for the 80 min cerium-treated electrode.

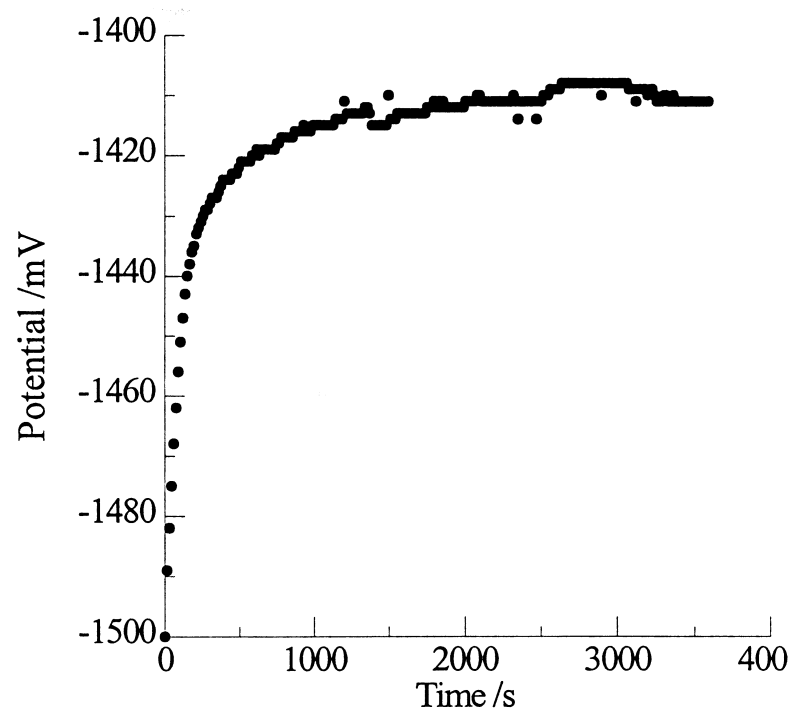

Fig. 1. The open-circuit potential of $\mathrm{Mg}$ as a function of time on immersion in a $50 \times 10^{-3} \mathrm{~mol} \mathrm{dm}^{-3}$ $\mathrm{Ce}\left(\mathrm{NO}_{3}\right)_{3}$ solution. 


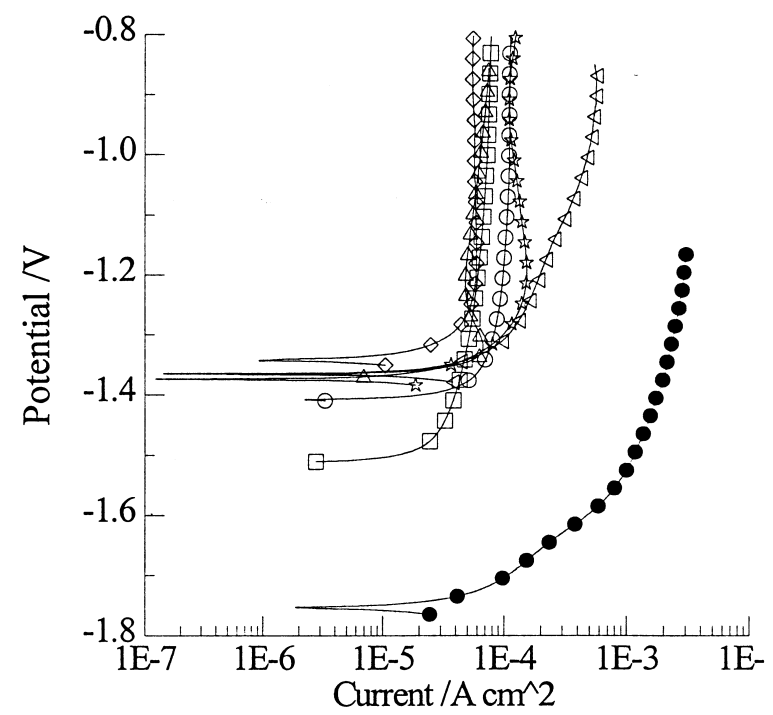

Fig. 2. Anodic polarisation plots of $\mathrm{Mg}$ untreated $\boldsymbol{O}$, following a 2 min cerium treatment $\bigcirc$, following a 5 min cerium treatment $\diamond$, following a 10 min cerium treatment $\triangle$, following a 15 min cerium treatment $\square$, following a 25 min cerium treatment $\downarrow$, and following a 80 min cerium treatment $\triangleleft$, in borate buffer solution.

In Fig. 3(a) and (b) the anodic polarisation plots recorded in the borate buffer solution for the untreated, cerium-treated, lanthanum-treated and praseodymiumtreated electrodes are shown for pure magnesium and the magnesium alloy, WE43, respectively. There appeared to be little difference in the electrochemical behaviour of the treated electrodes, with each of the treatments giving rise to a significant and similar reduction in the anodic current density. Similar data were recorded for the treated pure metal and alloy electrodes.

The cathodic polarisation behaviour of cerium-treated, lanthanum-treated and praseodymium-treated pure magnesium in the $\mathrm{pH} 8.4$ borate buffer solution is shown in Fig. 4. A considerable ennoblement in the corrosion potential is seen for all the treated samples. The slope calculated for the cerium-treated electrode in the -1.5 to $-1.8 \mathrm{~V}$ region was $-109 \mathrm{mV}$, and in -1.8 to $-2.6 \mathrm{~V}$ region was $-219 \mathrm{mV}$ per decade of current. The slope calculated for the untreated electrode in the -1.8 to $-2.0 \mathrm{~V}$ interval was $-110 \mathrm{mV}$ and in the -2.2 to $-2.6 \mathrm{~V}$ region was $-180 \mathrm{mV}$ per decade. This, together with the magnitude of the current suggests slightly faster reduction kinetics for the untreated magnesium electrode. Similar effects were observed for the conversion coatings formed on the magnesium alloy.

The OCP adopted by the cerium-treated, lanthanum-treated, praseodymiumtreated and untreated magnesium electrodes in the borate buffer solution is shown in Fig. 5 as a function of time. The OCP of the untreated electrode increased slightly on continued immersion; however, significant changes occurred for the treated electrodes. The potential of the treated electrodes decayed from relatively 

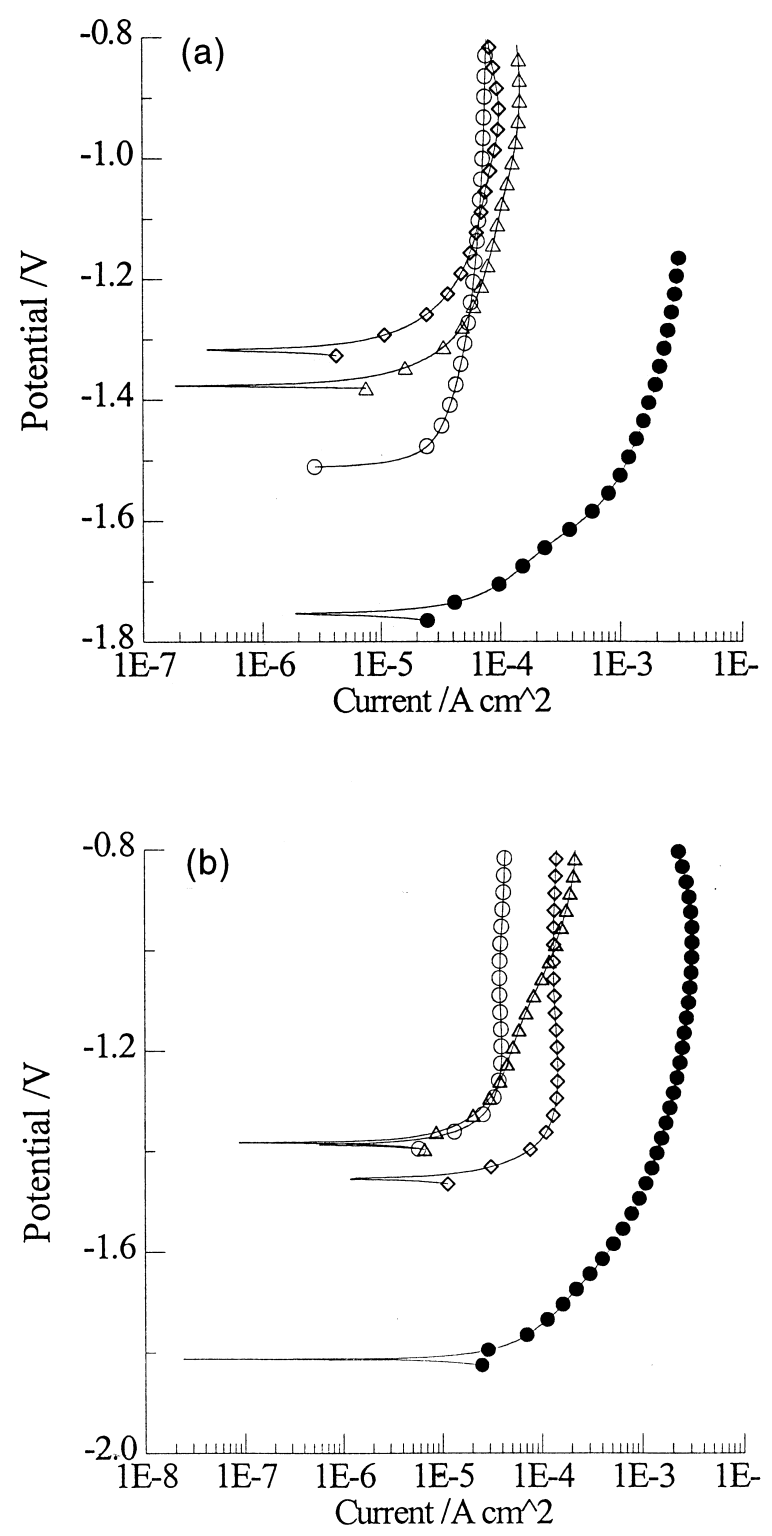

Fig. 3. (a) Anodic polarisation plots of $\mathrm{Mg}$ untreated $\boldsymbol{\bullet}$, cerium-treated $\bigcirc$, lanthanum-treated $\triangle$ and praseodymium-treated $\diamond$, in borate buffer solution; (b) Anodic polarisation plots of WE43 untreated -, cerium-treated $\bigcirc$, lanthanum-treated $\triangle$ and praseodymium-treated $\diamond$, in borate buffer solution. 


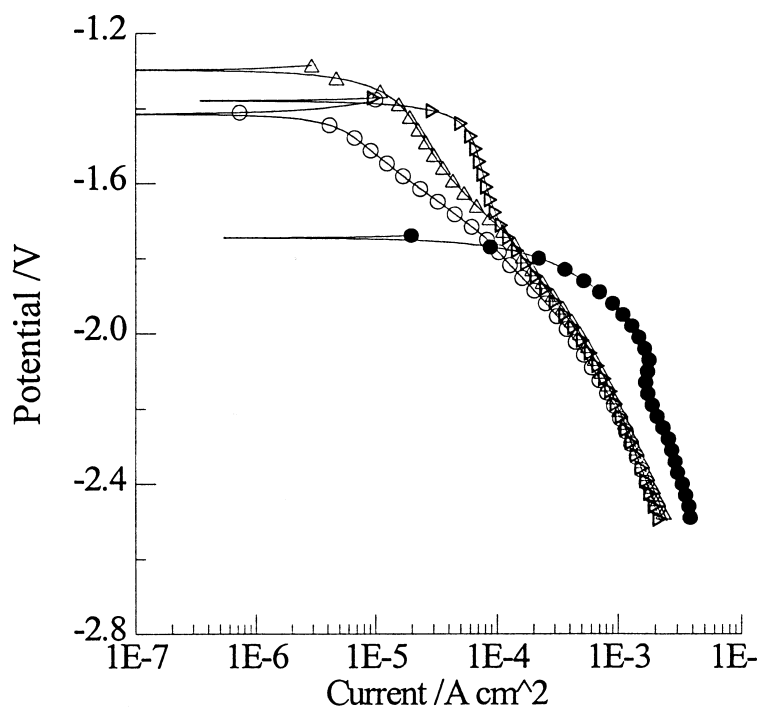

Fig. 4. Cathodic polarisation plots of $\mathrm{Mg}$ untreated $\boldsymbol{O}$, cerium-treated $\bigcirc$, lanthanum-treated $\triangle$, and praseodymium-treated $\triangleright$, in borate buffer solution.

noble values to a potential value in the region of $-1600 \mathrm{mV}$ with a slightly slower potential decay for the lanthanum-treated electrode. Similar effects were observed with the conversion coatings formed on the magnesium alloy.

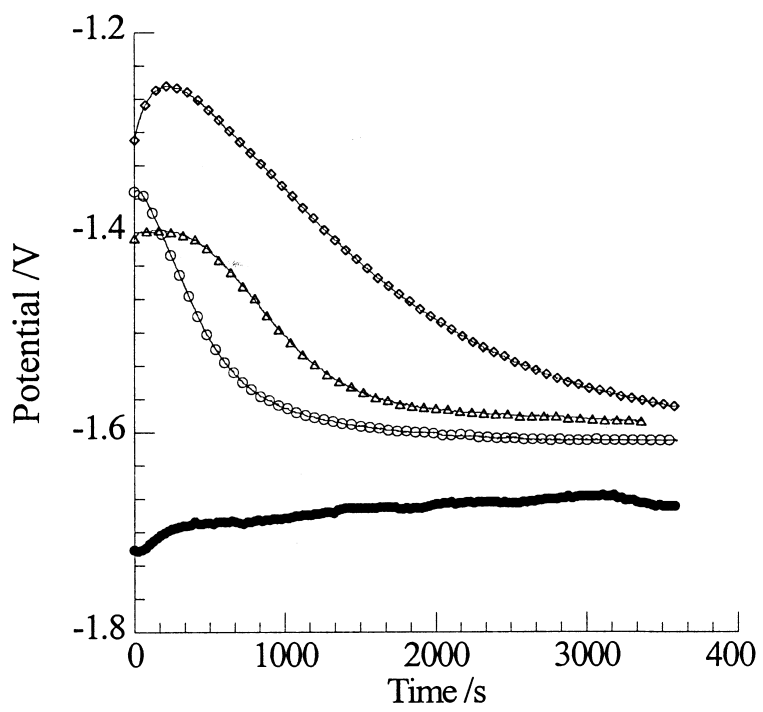

Fig. 5. Open-circuit potential as a function of time of $\mathrm{Mg}$ untreated $\boldsymbol{\bullet}$, cerium-treated $\bigcirc$, lanthanumtreated $\triangle$ and praseodymium-treated $\diamond$, in borate buffer solution. 

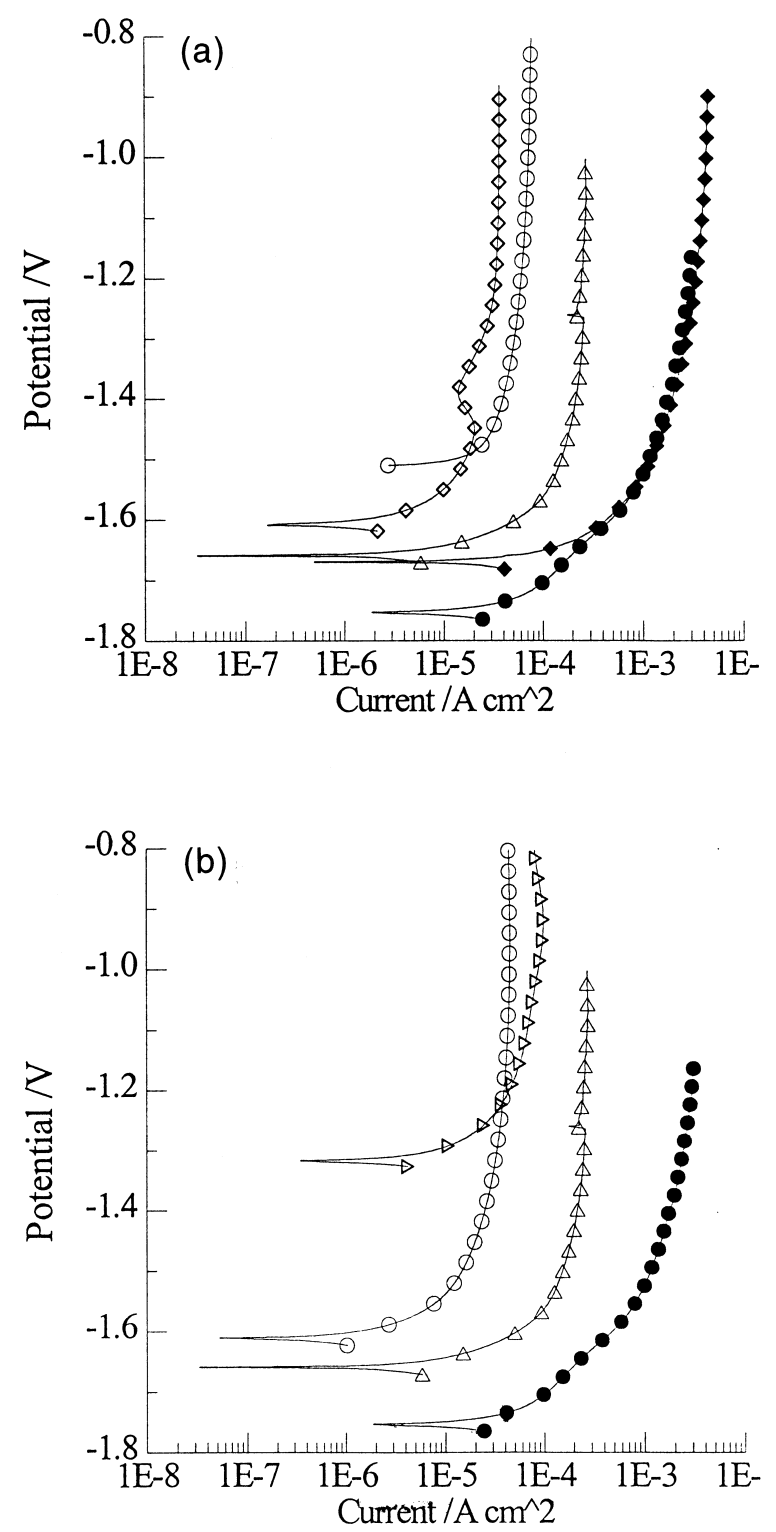

Fig. 6. (a) Anodic polarisation plots in borate buffer solution of $\mathrm{Mg}$ untreated $\boldsymbol{0}$, untreated and immersed in buffer solution for $1 \mathrm{~h} \diamond$, cerium-treated $O$, cerium-treated and immersed in buffer solution for $1 \mathrm{~h} \diamond$, cerium-treated and immersed in buffer solution for $15 \mathrm{~h} \triangle$; (b) Anodic polarisation plots in borate buffer solution of $\mathrm{Mg}$ untreated $\boldsymbol{\bullet}$, lanthanum- treated $\triangleright$, lanthanum-treated and immersed in buffer solution for $1 \mathrm{~h} \bigcirc$, lanthanum-treated and immersed in buffer solution for $15 \mathrm{~h} \triangle$; (c) Anodic polarisation plots in borate buffer solution of $\mathrm{Mg}$ untreated $\boldsymbol{\bullet}$, praseodymium-treated $\bigcirc$, praseodymium-treated and immersed in buffer solution for $1 \mathrm{~h} \diamond$, praseodymium-treated and immersed in buffer solution for $15 \mathrm{~h} \triangleright$. 


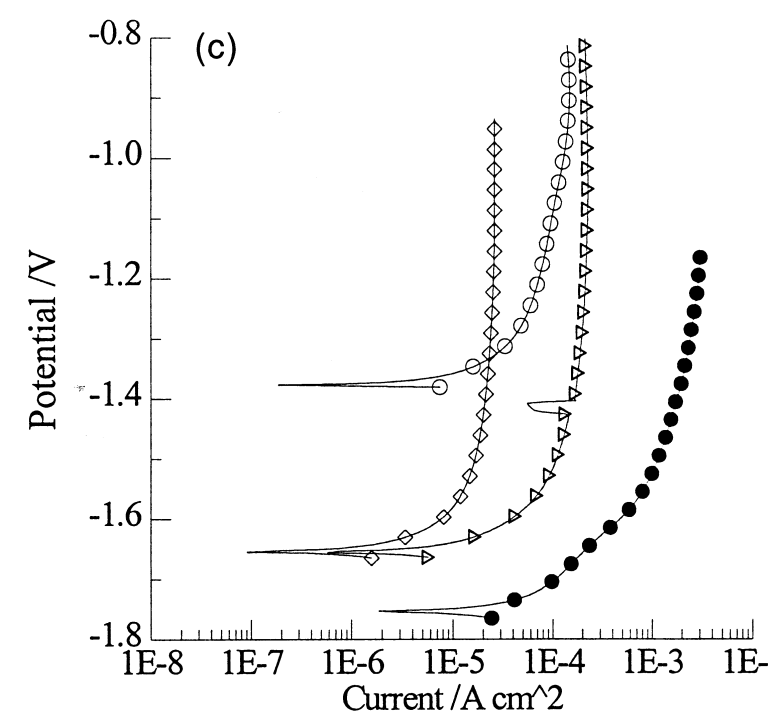

Fig. 6 (continued)

In order to test the stability of the conversion coatings over longer immersion times in the borate electrolyte, anodic polarisation plots and impedance data were recorded for the treated electrodes after different immersion periods. These data are presented in Figs. 6-8. In Fig. 6(a) the anodic polarisation behaviour of untreated magnesium, untreated and immersed in the buffer solution for $1 \mathrm{~h}$, cerium-treated, cerium-treated and immersed in the buffer solution for $1 \mathrm{~h}$, cerium-treated and immersed in the buffer solution for $15 \mathrm{~h}$ is shown. Similar data are presented for the lanthanum and praseodymium systems in Fig. 6(b) and (c), respectively. It is evident that the conversion coatings became more protective after a $1 \mathrm{~h}$ immersion period in the buffer solution. The anodic current density decreased by approximately $30 \mu \mathrm{A} \mathrm{cm} \mathrm{cm}^{-2}$ for the cerium coating and for the lanthanum coating and by approximately $70 \mu \mathrm{A} \mathrm{cm} \mathrm{cm}^{-2}$ for the praseodymium coating following $1 \mathrm{~h}$ immersion in the buffer solution. The coatings became less protective after a $15 \mathrm{~h}$ immersion period, as evident from the increases in the anodic current recorded for the treated electrodes immersed for $15 \mathrm{~h}$. Similar polarisation data were recorded for the treated alloy, Fig. 7. Again, the most significant decrease in the anodic current density, following the $1 \mathrm{~h}$ immersion period, was seen for the praseodymium-treated electrode. Although not shown here, longer immersion periods lead to a deterioration in the protective properties of the coating.

In Fig. 8(a) the impedance spectra recorded as a function of immersion time in the borate buffer solution are shown for the untreated magnesium electrode and the cerium-treated electrode. The symbols represent the experimental data and the solid lines represent the simulated data, generated using the equivalent circuit in 
Fig. 8(b). All spectra were recorded at the corrosion potential, and the first spectrum was recorded after a $1 \mathrm{~h}$ immersion period at which point the OCP had reached a stationary value. The spectra differ significantly for the treated and untreated electrodes. The presence of the cerium coatings can be seen clearly in the high-frequency region, from $10^{5}$ to $2 \times 10^{3} \mathrm{~Hz}$. Also, it is clear that the protective properties of the coating deteriorate with continued immersion in the buffer solution, as the impedance and phase angle maxima in this high frequency region decrease with increasing time. In the case of the cerium-treated electrodes the impedance spectra were fit to the equivalent circuit depicted in Fig. 8(b), which is similar to that used in previous studies [14-16]. $R_{\mathrm{S}}$ is the solution resistance, $R_{\mathrm{cf}}$ is the resistance of the cerium film, $Q_{\mathrm{cf}}$ is a constant phase element representing the intact film, $C_{\mathrm{dl}}$ is the capacitance of the underlying metal and $R_{\mathrm{p}}$ is its polarisation resistance. A simple Randles circuit was used to fit the untreated samples. Very good agreement between the experimental and simulated data was found as is evident in Fig. 8(a). The impedance of the constant-phase element, $Q_{\mathrm{cf}}$, is defined as $Z_{\mathrm{CPE}}=\left[Q_{\mathrm{cf}}(j \omega)^{n}\right]^{-1}$ where $-1 \leq n \leq 1$. In this case, the $n$ value was close to 0.5 indicating that this is a Warburg diffusional term. This is consistent with the fact that the coatings are somewhat porous allowing diffusion to the underlying substrate. The dependence of the other fitted parameters on immersion time in the buffer solution is illustrated in Fig. 9(a)-(c). $R_{\mathrm{cf}}$ decreased from about 800 to $150 \Omega \mathrm{cm}^{2}$ over the $10 \mathrm{~h}$ immersion period, Fig. 9(a), due to

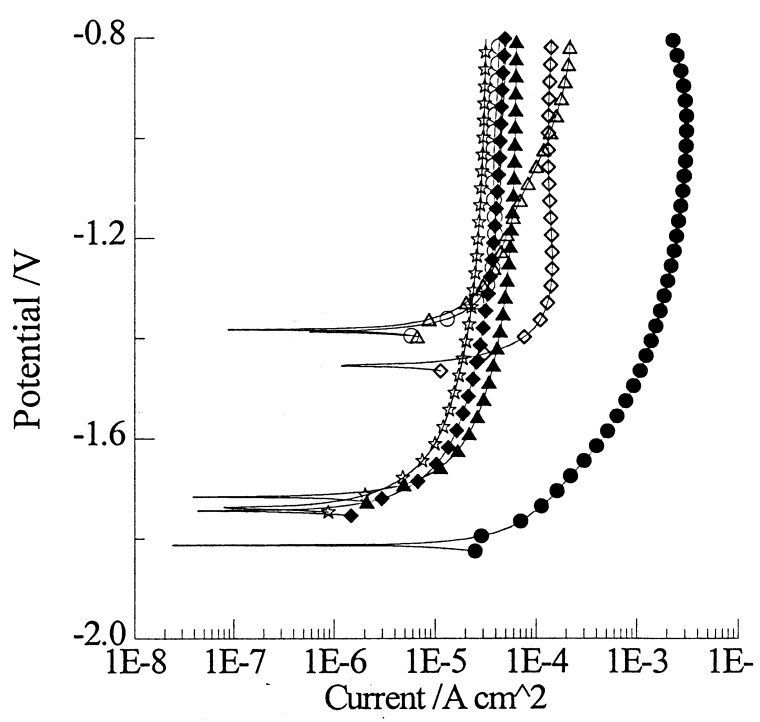

Fig. 7. Anodic polarisation plots in borate buffer solution of WE43 untreated $\boldsymbol{Q}$, cerium- treated $\bigcirc$, lanthanum-treated $\triangle$, praseodymium-treated $\diamond$, cerium-treated and immersed in buffer solution for $1 \mathrm{~h}$ $i s$, lanthanum-treated and immersed in buffer solution for $1 \mathrm{~h} \mathbf{\Delta}$, praseodymium-treated and immersed in buffer solution for $1 \mathrm{~h}$ 

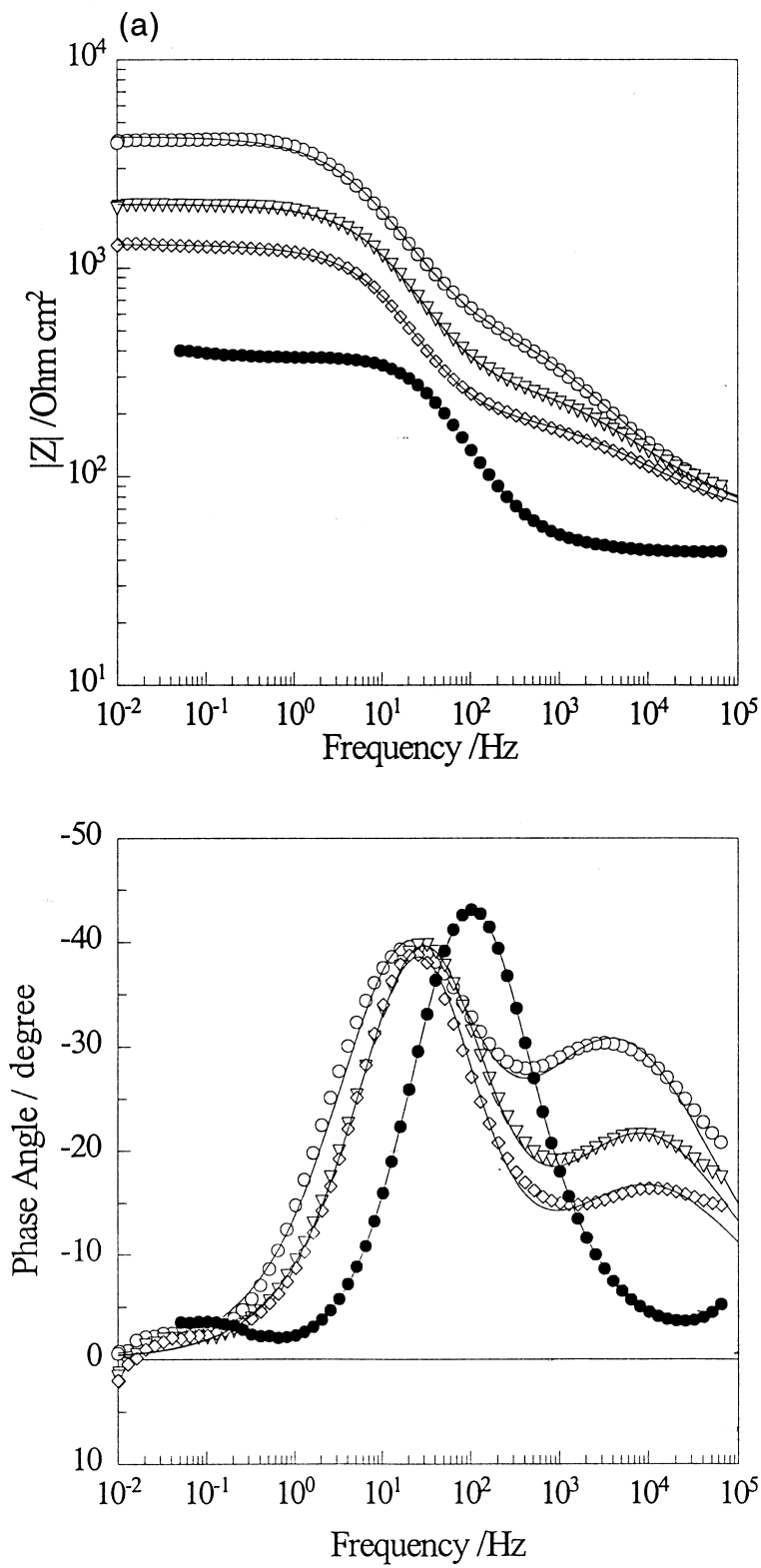

Fig. 8. (a) Impedance spectra recorded in borate buffer solution for $\mathrm{Mg}$ untreated and $1 \mathrm{~h}$ immersion ๑, cerium-treated and $2.5 \mathrm{~h}$ immersion $\bigcirc$, cerium-treated and $5 \mathrm{~h}$ immersion $\triangle$ and cerium-treated and $10 \mathrm{~h}$ immersion $\diamond$; (b) Equivalent circuit used to fit coated data. 


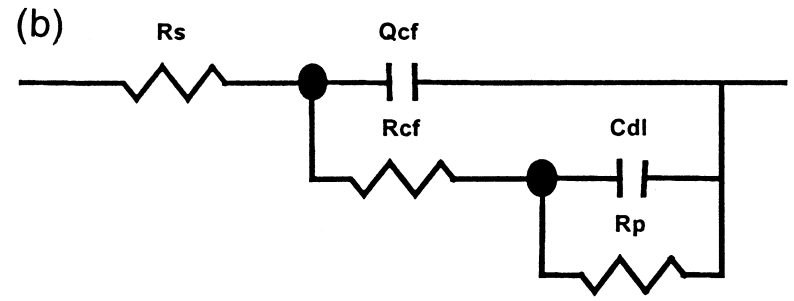

Fig. 8 (continued)

deterioration of the coating. The polarisation resistance of the underlying metal decreased in a similar fashion, Fig. 9(b), but even after the $10 \mathrm{~h}$ period the polarisation resistance of the treated electrode was approximately a factor of three greater than that for the untreated electrode. The deterioration of the cerium coating and increase in the active area of the underlying magnesium electrode are also evident from the variations in the capacitance of the metal, Fig. 9(c). The capacitance $C_{\mathrm{dl}}$ of the untreated electrode reached a stationary value of approximately $40 \mu \mathrm{F} \mathrm{cm}{ }^{-2}$. The capacitance of the treated electrode increased from less than 10 to about $25 \mu \mathrm{F} \mathrm{cm} \mathrm{cm}^{-2}$ over the $10 \mathrm{~h}$ period. Similar data were recorded for the lanthanide and praseodymium coatings.

\section{Discussion}

The results presented here demonstrate that the corrosion resistance of magnesium and a magnesium alloy, WE43, can be increased considerably, at least for short periods of time, by applying a cerium, lanthanum or praseodymium passivation treatment/conversion coating to the metal or alloy. The coatings are formed during the intense dissolution of magnesium in the acidic treatment solutions. The potential decays as the coating forms, from -1500 to about -1430 $\mathrm{mV}$ (SCE) Fig. 1, with the nucleated coatings providing a barrier between the aggressive solution and the metallic surface, as is evident from the impedance data, Fig. 8.

It is accepted generally that the hydrogen evolution reaction is the predominate reduction reaction in this type of environment, [4]

$$
2 \mathrm{H}_{3} \mathrm{O}^{+}+2 \mathrm{e}^{-} \rightarrow \mathrm{H}_{2}+2 \mathrm{H}_{2} \mathrm{O}
$$

As this reaction proceeds, local areas of alkalinity are established at which points the precipitation of rare earth oxides/hydroxides occur. This conclusion is in agreement with other studies [5]. The coatings appeared to nucleate in a similar fashion on pure magnesium and the magnesium alloy, with the presence of the alloying additions in the magnesium alloy having little effect. On further immersion of these coatings in a $\mathrm{pH} 8.5$ buffer solution, a solution in which the 

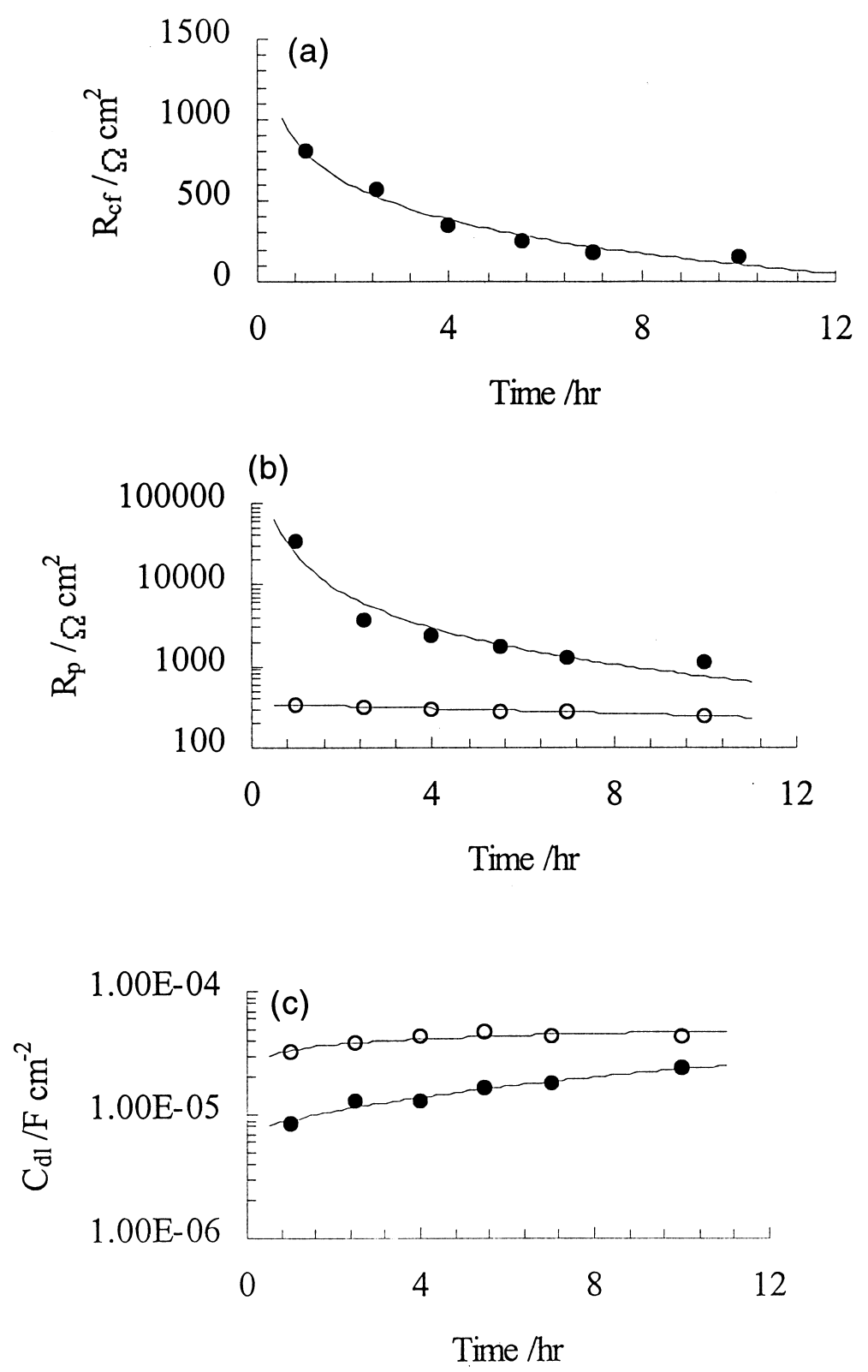

Fig. 9. (a) Coating resistance, $R_{\mathrm{cf}}$, as a function of immersion time in buffer solution; (b) Polarisation resistance, $R_{\mathrm{p}}$, for $\mathrm{Mg}$ untreated $\bigcirc$, and cerium-treated $\bigcirc$ as a function of immersion time in buffer solution; (c) Capacitance, $C_{\mathrm{dl}}$, as a function of immersion time in borate buffer solution for $\mathrm{Mg}$ untreated $\bigcirc$, and cerium-treated 
untreated samples dissolve, the coatings first exhibited an increase in their protective nature, Figs. 6 and 7, before deteriorating after several hours of immersion, Figs. 6 and 8. The initial modification of the coatings on immersion in the $\mathrm{pH} 8.5$ buffer solution is probably associated with the build-up of magnesium corrosion products and the formation of mixed magnesium/rare earth oxide/ hydroxide coatings. This modification occurs during the early stages of immersion, as is evident from the potential decay profiles shown in Fig. 5. During the first $1000 \mathrm{~s}$, the OCP changed by approximately $200 \mathrm{mV}$ for the coating formed in the cerium solution with similar changes occurring for the lanthanum and praseodymium-treated samples.

The presence of the REMS coatings and their deterioration with increasing exposure time are clearly evident from the impedance spectra shown in Fig. 8. Here, two distinct phase angle maxima were observed, the high-frequency one being associated with the cerium coating/film and the low-frequency one being associated with the properties of the substrate material exposed in pores of the coating. This can be deduced from a comparison of the impedance data in Fig. 8. The dependence of the cerium film resistance, the polarisation resistance and capacitance of the substrate magnesium on time clearly demonstrated that the cerium coating deteriorated with prolonged immersion in the buffer solution. It is unlikely that the cerium coating dissolves under such $\mathrm{pH}$ conditions. Rather, it appears that electrolyte penetration occurred through pores in the coating, reacting with the underlying magnesium substrate and resulting in the formation of magnesium hydroxy corrosion products which in turn destabilised the coating by increasing its porosity. This conclusion is consistent with the decrease in the cerium film resistance, $R_{\mathrm{cf}}$.

\section{Conclusions}

Treatment of pure magnesium and a magnesium alloy, WE43, in cerium, lanthanum and praseodymium-containing solutions has lead to a significant increase in the corrosion resistance of magnesium in a $\mathrm{pH} 8.5$ buffer solution. Although the coatings began to deteriorate on prolonged immersion in the buffer solution, the coatings still provided a three-fold increase in the polarisation resistance of magnesium after a $10 \mathrm{~h}$ period of exposure to the aggressive test solution. Future work will concentrate on increasing the corrosion resistance of the coatings formed on magnesium and its alloys by immersion in REMS solution using additional treatments to seal these coatings immediately after their formation.

\section{Acknowledgements}

This work was in part supported by a NATO Collaborative Research Grant (950593) and by Forbairt, under the Basic Science Research Grants Award, SC/ $96 / 456$. 


\section{References}

[1] G.L. Maker, J. Kruger, J. Electrochem. Soc 137 (1990) 414.

[2] I.J. Polmear, Light Alloys, Metallurgy of the Light Metals, 2nd ed, Arnold, Paris, 1989.

[3] G. Song, A. Atrens, D. St John, X. Wu, J. Nairn, Corrosion Sci 39 (1997) 1981.

[4] E.F. Emley, Principles of Magnesium Technology, Pergamon Press, Oxford, 1966.

[5] B.P.F. Goldie, J.J. McCarroll, Australian Patent, AU-32947/84, 1984.

[6] D.R. Arnott, N.E. Ryan, B.R.W. Hinton, B.A. Sexton, A.E. Hughes, Appl. Surf. Sci 23 (1985) 236.

[7] D.R. Arnott, B.R.W. Hinton, N.E. Ryan, Corrosion 45 (1989) 12.

[8] B.R.W. Hinton, D.R. Arnott, N.E. Ryan, Materials Forum 9 (1986) 162.

[9] R.B.W. Hinton, J. of Alloys and Compounds 180 (1992) 15.

[10] F. Mansfeld, Y. Wang, Br. Corros. J 29 (1994) 194.

[11] F. Mansfeld, Y. Wang, H. Shih, J. Electrochem. Soc 138 (1991) L74.

[12] Y.C. Lu, M.B. Ives, Corros. Sci 34 (1993) 1773.

[13] A.J. Aldekiewicz, H.S. Isaacs, A.J. Davenport, J. Electrochem. Soc 142 (1995) 3342.

[14] G.W. Walter, Corros. Sci 26 (1986) 681.

[15] F. Mansfeld, M.W. Kendig, S. Tsai, Corrosion 38 (1982) 478.

[16] F. Mansfeld, J. Appl. Electrochem 25 (1995) 187. 